\title{
La filosofía japonesa en español
}

\section{Emiliano Castro Sánchez}

James W. Heisig et al., La filosofía japonesa en sus textos. Barcelona, Herder, 2016. 1352 pp.

\section{La filosofía japonesa}

J

apón es una tierra que nunca fue colonizada. Al menos no en el sentido en que América, África o India lo fueron. Tal vez por ser una isla o por su accidentada geografía o su propensión a los sismos o por su lejanía, pero de algún modo se salvó del destino de otras latitudes. Esto ha permitido a Japón mantener un ecosistema intelectual muy particular, lleno de conceptos endémicos.

De cualquier forma, este ecosistema siempre ha sido determinado por el diálogo. Desde que tribus nómadas quedaron varadas en la isla al subir el nivel del mar después de la última glaciación, teniendo que vérselas con un nuevo e implacable medio, Japón se ha ido construyendo históricamente como el encuentro con lo otro. Tiempo después, llegaría un nuevo mundo desde el otro lado del mar. En el año 552 d. C. un rey del oeste de la actual Corea envió una embajada al emperador del joven pueblo del sol naciente que incluía monjes y textos sagrados de la tradición budista. ${ }^{1}$ Esta nueva tradición introduciría todo un mundo nuevo a Japón. Con el budismo vino toda la cultura de la costa occidental del mar. A partir de este punto, China se volvió un polo de referencia para la cultura japonesa junto con un budismo ya muy teñido tanto por el taoísmo como por el confucianismo chinos.

Este segundo encuentro haría que, frente a estos nuevos saberes extranjeros, los japoneses se preguntaran por su propia identidad. De este diálogo con el continente, a partir del budismo, nació una nueva identidad. Ante el camino del Buda traído de ultramar, las creencias locales se fueron agrupando y englobando en el camino de los dioses de la tierra japonesa: el shinto.

${ }^{1}$ Que había llegado desde India a Extremo Oriente, básicamente a China, desde el siglo II a. C. Pero no se consolidaría hasta el siglo v con las traducciones de Kumarajiva. 
Tiempo después, el continente traería una nueva revolución en el mundo japonés. En 1223 el monje japonés Dōgen de 23 años decidió cruzar el mar rumbo a China a buscar la verdadera práctica del camino de Buda. Al volver dijo sólo haber aprendido que los ojos son horizontales y la nariz vertical, cuando la mayoría de los "becarios" que viajaban a China desplegaban una larga lista de lecturas, maestros y hazañas para justificar su viaje. Junto con esta enseñanza, Dōgen trajo enseñanzas del budismo ch'an de China, zen en japonés. En los mismos tiempos, otros monjes se rebelaron contra el elitismo del budismo de su tiempo y crearon una nueva forma de budismo para todos, un budismo que no se reducía a la élite de "calvos" sino que enseñaba a los campesinos, y a quien los escuchara, que bastaba con decir con el corazón puro sólo una vez el nombre de Buda para que éste nos llevara a su tierra y nos liberara del sufrimiento. A este budismo se le llama "budismo de la tierra pura", budismo shin, y es hoy la rama con más adeptos en Japón.

Este enfrentamiento entre el ceremonioso y elitista budismo tradicional y las nuevas escuelas revolucionarias tuvo un correlato político. El emperador fue volviéndose una figura con cada vez más peso cultural que político y fue naciendo una casta de familias guerreras que se hicieron del poder político. El poder político cambiaría ahora de manos cada vez que una familia era desplazada por otra. Poco a poco, esta nueva clase guerrera saldría a buscar su propia identidad en diálogo con las tradiciones intelectuales y culturales existentes.

En el siglo XVII se daría otro gran cambio en la relación entre Japón y el mundo. Durante el periodo Edo, el shogunato empezó una persecución contra el catolicismo al verlo como un peligro para la estabilidad de la nación. Esto llevó a que, en 1644, Japón cerrara sus fronteras. Se impuso el registro de toda la población por medio de las instituciones religiosas y se restringió el contacto con el resto del mundo a chinos y holandeses. Japón permanecería cerrado al mundo casi de manera total, al menos culturalmente, hasta que los barcos militares del comandante Matthew Perry llegaron a las costas japonesas a imponer la apertura comercial en 1853. Este impacto fue tan fuerte que, en poco más de una década, terminó con el gran poder hegemónico del Shogun del periodo Edo y dio inicio a la Restauración Meiji en 1868.

A partir de entonces, Japón entraría de golpe al mundo, incluido el mundo de la filosofía occidental. Una generación de jóvenes fue enviada a estudiar al extranjero, básicamente a Alemania y Francia, y se fue imponiendo la educación universitaria de estilo occidental por encima de las instituciones tradicionales. ${ }^{2}$ Aquí podemos decir que empieza la filosofía japonesa en sentido

${ }^{2}$ Cosa a la que Nishida se opusó en su juventud al negarse a matricularse en una carrera y, más bien, cursando sus estudios universitarios como lo que hoy llamaríamos "oyente". 
occidental (o sea de esa tradición que empieza en Grecia y llega hasta Kant, Hegel o Nietzsche). Aunque hay referentes anteriores, se suele decir que la filosofía japonesa empieza en 1911, cuando un oyente de distintas clases en la Universidad de Kioto, Nishida Kitaro, publica Indagación sobre el bien.

La filosofía japonesa (en el sentido ya aclarado) sería siempre una filosofía también dialógica. Una filosofía en que se pondría a dialogar a los autores occidentales recientemente aprendidos (Kant, Hegel, Kierkegaard, Heidegger, Whitehead, Marx) con las tradiciones japonesas, particularmente con el budismo. A su vez, los pensadores buscarán responder a los nuevos desafíos planetarios desde este diálogo. Nishitani comenta que Japón empieza a absorber la cultura europea cuando ésta se encuentra en crisis, una crisis que Nietzsche bautizó con el nombre de "nihilismo". Esta forma dialógica de hacer filosofía se puede ver claramente ilustrada por la llamada escuela de Kioto.

Estas preocupaciones no serían exclusivas de los filósofos. Se generalizará la idea en los círculos intelectuales en la tercera y cuarta década del siglo Xx de que la cultura occidental tiene una propensión egoísta e imperialista que devora las otras culturas e impone la suya como universal, simbolizada principalmente por la cultura estadounidense. Frente a esto, la única gran potencia cultural capaz de resistir es la tierra que nunca ha sido sometida por los poderes coloniales, cuya cultura y cuyo linaje real no han sido quebrantados por fuerzas externas. Esta contraposición entre dos proyectos históricos dará para mucha discusión filosófica entre pensadores como Nishida, Tanabe, Watsuji, Suzuki, Nishitani y Miki. Se fue alimentando la idea de que Japón podía crear una esfera de coprosperidad en Asia del este para resistir a la embestida imperialista. Una especie de proyecto decolonial en Extremo Oriente. El problema es que esto sirvió para justificar la invasión de Corea, China y, finalmente, la entrada a la guerra del pacífico en la Segunda Guerra Mundial. Esta entrada a la guerra terminaría con una apabullante derrota y con la catástrofe de Hiroshima y Nagasaki.

Después de la guerra, Japón se ha ido occidentalizando cada vez más. Esto ha dado nuevos aires a la filosofía japonesa. Desde la posguerra muchos autores reformularon sus planteamientos, otros se volvieron abiertos críticos del pensar anterior y toda una nueva generación entró en escena. En general, después de la guerra, la mira de la filosofía japonesa se amplió, los problemas ya no eran sólo japoneses sino los problemas del presente. La discusión igualmente se amplió para incluir a autores cristianos más abiertamente, buscando un campo de diálogo con Occidente.

En el siglo XXI, mientras los departamentos de filosofía japonesa no se diferencian en mucho de los departamentos de cualquier otro lugar (por ejemplo, no se enseñan a autores budistas o shintoistas), las traducciones a lenguas occidentales han llevado a la filosofía nacida en Japón a abrirse paso al debate 
filosófico mundial, haciendo nacer intereses en diversos campos y latitudes. Esos problemas y conceptos que se fueron reproduciendo y evolucionando en el ecosistema intelectual japonés, al calor de los duros diálogos que lo determinaron, han ido abriéndose paso a nuevos territorios y ecosistemas donde han encontrado nuevos desarrollos. Hoy el carácter dialógico del pensar japonés se encuentra en una nueva dimensión al encontrar interlocutores occidentales dispuestos a responder a la interpelación del pensamiento japonés. Esto va haciendo de la filosofía una empresa más incluyente y completa, y más aún, abre un montón de caminos nuevos, nuevos comienzos, para una filosofía occidental sumida en la crisis.

\section{La filosofía japonesa en sus textos}

Una prueba de cómo este nuevo episodio del pensar japonés ha rebasado las fronteras de la isla es justamente el trabajo La filosofía japonesa en sus textos. En 2011 vio la luz el Japanese Philosophy a Sourcebook, un monumental trabajo que agrupó a los más reconocidos especialistas en filosofía japonesa, dentro y fuera de Japón, en un intento de crear un gran catálogo o carta de presentación de la filosofía japonesa para el mundo. Esta empresa tomó siete años y requirió la cooperación de más de 100 especialistas en distintos aspectos de la filosofía japonesa y de todos los rincones del mundo. El texto pretendió ofrecer un mapa de la filosofía japonesa. Divide su exposición en apartados abocados a las más importantes corrientes del pensamiento japonés. Expone a los más importantes autores de éstas a través de una introducción contextual y una selección de fragmentos de sus textos más relevantes.

El texto apareció originalmente en inglés, siendo una primera ventana para el público occidental. Pero también se convirtió en un gran glosario para la traducción de la filosofía japonesa al inglés. Curiosamente, uno de los primeros problemas de la filosofía occidental al llegar a Japón fue el de encontrar traducciones para sus conceptos tradicionales como sustancia, existencia, subjetividad o similares. Lo mismo pasa en sentido contrario cuando se intenta traducir a lenguas occidentales la filosofía japonesa. Una lengua es un horizonte de sentido y la traducción implica el diálogo entre dos horizontes. Esto se ve con total claridad al traducir horizontes tan disímiles hasta en sus escrituras. Así pues, si bien el Sourcebook no es la primera traducción de textos filosóficos japoneses al inglés, sí implicó traducir, junto con los fragmentos más significativos, los conceptos más relevantes de la filosofía japonesa y tenerlos todos juntos en una obra. Con ello, las traducciones de conceptos clave de la filosofía en el Sourcebook se han convertido en referentes, al menos para la crítica. 
Junto con una introducción a la filosofía japonesa, el Sourcebook compila toda una jerga para hablar de filosofía japonesa en inglés. En cierto sentido, eso significa introducir la filosofía de un horizonte a otro, traducirla. Y, en ese esfuerzo de traducción, se termina configurando un nuevo lenguaje que ya no es ninguno de los originales sino la jerga del encuentro. El Sourcebook ofrece la jerga del encuentro entre la filosofía japonesa y el inglés.

Pero, al aparecer La filosofía japonesa en sus textos, que busca ser una versión en español del Sourcebook, las y los colegas no se limitaron a traducir la jerga inglesa al español sino que, en un nuevo esfuerzo monumental de traducción, volvieron a confrontarse con los originales. Al hacer la versión del Sourcebook en español, tradujeron las introducciones desde el texto en inglés, pero volvieron a confrontar las traducciones de los fragmentos de textos con los originales en japonés. Esto puede parecer una innecesaria repetición del trabajo, pero es justo la mayor y más sorprendente aportación de esta obra. Como dije antes, los lenguajes son horizontes de sentido. Los largos debates sobre la traducción nos han mostrado que traducir no es sustituir una palabra de una lengua a otra. Esto porque ni existe tal equivalencia ni las palabras pueden verse de forma independiente de todo un contexto de sentido. Así pues, vistos a la luz del español, los textos de la filosofía japonesa se transforman, ganan nuevas dimensiones y posibilidades de sentido. Confrontar los textos con una lengua nueva no implica repetir el trabajo, si no abrir un diálogo nuevo entre otros dos horizontes de sentido.

El trabajo de La filosofía japonesa en sus textos nos da al español lo que el Sourcebook ofreció al inglés, una jerga de diálogo con la filosofía japonesa; cosa que no se habría logrado con una simple traducción del inglés. Esto es de capital importancia para los hispanoparlantes que estamos interesados en el diálogo con la filosofía japonesa. Hasta ahora, quienes no tenemos acceso a los textos originales en japonés, hemos tenido que entablar el diálogo a partir de las versiones en inglés principalmente. El problema es que esto implica una triangulación en que el inglés se confronta con el japonés y luego nuestro horizonte en español con el inglés. Dicha triangulación nos lleva, en cierto sentido, a pensar la filosofía japonesa en inglés, llevándonos incluso a sacar del inglés algo de nuestra jerga para hablar de filosofía japonesa.

Esta nueva jerga en español lograda por La filosofía japonesa en sus textos espero nos sirva para ir liberando las posibilidades de pensar la filosofía japonesa en español, con las posibilidades que nuestra lengua y nuestros horizontes abren. Esta nueva confrontación con la filosofía japonesa desde el español nos abre la posibilidad de dialogar desde nuestra lengua materna y ahí encontrar los límites no explorados de esta naciente jerga filosófica españolajaponesa. 


\section{Sus textos}

El libro comienza con una versión en español de la introducción original del profesor John Maraldo. Este texto es una de las más importantes aportaciones al debate sobre la caracterización de la filosofía japonesa. Discute la idea de traducción como encuentro filosófico.

A continuación, se presenta "La constitución de Shotoku", considerado uno de los primeros textos con contenido filosóficos en Japón, de 604. En este texto ya se ve la tensión clásica del pensamiento japonés entre las influencias externas del confucianismo y budismo chinos, y la forma particularmente japonesa de formular las cuestiones.

Después hay un primer apartado dedicado a la tradición budista clásica en Japón. Aquí figura Kukai, fundador de la escuela Shingon de budismo, escuela enfocada a la perfección de prácticas rituales como vías para desdibujar el yo y canalizar en la acción desinteresada a Dainichi, el Buda cósmico. Esta escuela propone una cierta hermenéutica de la vida, ofreciendo una lectura exotérica y otra esotérica de las acciones cotidianas, siendo esta última una vía de mostración de la realidad última en la cotidianidad, a través de las claves interpretativas del ritual.

También se habla de los debates sobre la iluminación original de los seres (es decir, sobre si todos los seres tienen la posibilidad de liberarse del sufrimiento o unos sí y otros no) que dio su identidad a la escuela Tendai. Esta escuela, caracterizada por el énfasis en el estudio de sutras y comentarios, sería la incubadora de muchos movimientos revolucionarios en el budismo japonés. Igualmente, en este apartado figura Nichiren, un personaje algo misterioso para Occidente pero, a la vez, uno de los más importantes y originales del budismo japonés, siendo su enseñanza la base de movimientos religiosos como el Soka Gakkai, uno de los que tienen mayor seguimiento e influencia en Japón.

Luego viene un apartado dedicado al zen, una de las corrientes que caracterizan la recepción de la filosofía japonesa en Occidente. Aquí se le dedica un apartado a Dōgen, una de las figuras intelectuales más importantes del pensamiento japonés y fundador de la escuela zen Soto (enfocada en la meditación). Descrito a veces como un Tomás de Aquino del pensamiento zen. Sobresale en este apartado una traducción de "uji", un texto dedicado a la equiparación de tiempo y existencia. El texto se centra en la polisemia de "uji" que refiere a la vez al tiempo y presencia. Esto hace muy complejo traducir dicho concepto y, con él, el texto. En la traducción que nos ocupa se inclinaron por usar "momento existencia" para traducir "uji". También en el apartado de zen figuran Ikkyu Sojun (un monje zen heterodoxo, poco apegado a las instituciones y normas monásticas, famoso por el uso del humor y por su gran habilidad literaria) junto con una traducción de "Esqueletos", un bellísimo 
trabajo que explora la experiencia del precursar la muerte como vía para la liberación. Vale mencionar también a Hakuin, un monje zen Rinzai famoso por su radical práctica del koan (acertijos verbales diseñados para deconstruir la subjetividad), y Hisamatsu Shin'ichi, un profesor universitario que durante un retiro alcanzó el despertar y se sumó a la práctica monástica del zen. Hisamatsu es considerado una de las figuras representantes del movimiento contemporáneo de "budismo comprometido" en Japón.

Después hay un apartado dedicado a la tradición de la tierra pura. Otro movimiento budista revolucionario en Japón, orientado en contra del elitismo monástico y dirigido al pueblo. Aquí podemos encontrar a las figuras fundamentales de esta escuela como Honen y Shinran; y podemos leer en ellos la conformación de los cánones de la corriente Shin.

A continuación, hay un apartado dedicado al confucianismo, la gran escuela china de ontología política en Japón. Luego, hay un apartado dedicado al Shinto y los estudios nativos. Se trata de los esfuerzos del pensar japonés por encontrar una identidad en sus orígenes. Aquí sobresale el apartado dedicado a Motori Norinaga, considerado el pionero de los estudios nativos con su Kojiki-den, uno de los libros más importantes y difundidos en la historia de Japón, y su búsqueda del lenguaje japonés original y, en él, las señas de los orígenes del pueblo del sol naciente.

Posteriormente, entra en escena la filosofía académica en Japón, conformada al calor de la apertura a Occidente. Aquí veremos las primeras confrontaciones con la filosofía occidental, los primeros intentos de traducirla e incluso la acuñación de tetsugaku, el término japonés para filosofía. Éste es el inicio de la irrupción del pensamiento japonés en el panorama planetario.

Adelante se le dedica un amplio apartado a la escuela de Kioto, la primera escuela filosófica en sentido occidental nacida en Japón y que hoy tiene presencia en todo el globo. No abundaré mucho aquí, pues es probablemente esta la escuela más conocida de la filosofía japonesa. Sólo me gustaría llamar la atención sobre personajes como Miki que han pasado en buena medida por abajo del radar de los estudiosos occidentales. Pensadores forjados al calor de la dura situación política e intelectual de Japón en el siglo Xx.

En el apartado siguiente, "Filosofía del siglo xx", encontramos un montón de pensadores poco conocidos en Occidente, pero sobre manera interesantes. Por ejemplo, Wátsuji y su respuesta temprana a Heidegger con el "ser en el espacio" y el estudio de lo que llama "paisaje". También tenemos a Kuki, quien diera una de las primeras introducciones a la filosofía japonesa en suelo occidental, un personaje vinculado históricamente con Sartre, Heidegger y Löwith. Otro más es Yusa, con su trabajo sobre la corporalidad como un "entre" ni objetivo ni subjetivo desde la perspectiva de las prácticas performáticas extremo-orientales. También, su trabajo sobre la sincronicidad jungiana da mucho a discutir todavía. 
En cuanto al apartado de "Cultura e identidad", me gustaría resaltar la importancia de "Las discusiones Chuokorono (1941-1942)" y "Superar la modernidad: un simposio (1942)". Estos apartados me parecen particularmente importantes, ya que son las primeras presentaciones en español de los debates en torno al nacionalismo, militarismo y la participación japonesa en la Segunda Guerra Mundial. Estas discusiones casi no han llegado a nuestra lengua y puede ser una interesante discusión. Creo que no hace mucho la Universidad de Columbia publicó el simposio de "Superar la modernidad" en inglés y los textos revelan interesantes debates sobre la globalización occidental, la identidad, la sociedad del espectáculo y el poder. Esperemos que esta nueva ventana al debate en nuestra lengua nos permita adentrarnos en la discusión.

También es de resaltar el apartado "Filósofas", ésta fue una innovación del Sourcebook que ahora La filosofía japonesa en sus textos acompaña. Al realizar el Sourcebook se comisionó a mujeres especialistas en el pensamiento japonés a buscar a las filósofas más relevantes de la tradición japonesa, hasta ese momento mayormente desconocidas. Este trabajo abrió la caja de pandora de un montón de pensadoras bastante interesantes que hasta ese momento estaban silenciadas por el peso de los hombres en la escena filosófica. Desgraciadamente, este fenómeno de exclusión de la voz femenina se ve en toda la historia de la filosofia, excluyendo a la mitad de la humanidad de la posibilidad de entrar al diálogo del pensar. La filosofía japonesa en sus textos, nos ofrece también la primera presentación de las pensadoras japonesas más relevantes al español.

Mucho más podría decir sobre el apartado de estética o el bastante desmitificante apartado sobre el pensamiento samurái; pero lo mejor es dejar eso al lector interesado en asomarse al nuevo mundo de la filosofía japonesa en español. Quiero agradecer de todo corazón a Raquel Bouso y a las y los colegas de la Pompeu Fabra por ir abriendo camino para la filosofía japonesa en español. Acá en México el trabajo está todavía en pañales (exceptuando, claro, los trabajos pioneros de Jacinto Zavala) pero ya ha arrojado grandes resultados. Esperamos que esta nueva ventana hispanoparlante nos sirva para encontrar un diálogo nuestro con el pensamiento japonés y, más aún, sea un medio hábil para encontrarnos a nosotros mismos más allá de nuestros horizontes. 